\title{
Characterization of a Pleiotropic Succinate Dehydrogenase-negative Mutant of Bacillus subtilis
}

\author{
By KERSTIN MAGNUSSON, * BLANKA RUTBERG, LARS HEDERSTEDT \\ AND LARS RUTBERG \\ Department of Bacteriology, Karolinska Institute, Box 60400, S-104 01 Stockholm, Sweden
}

(Received 5 October 1982; revised 25 November 1982)

\begin{abstract}
A succinate dehydrogenase-negative mutant of Bacillus subtilis is described which lacks all three subunits of the membrane-bound succinate dehydrogenase complex : flavoprotein, iron protein, and cytochrome $b_{558}$. The corresponding mutation is revertible and it maps at one extreme of the $s d h$ region. The results presented suggest that the structural genes for the subunits of the succinate dehydrogenase complex are part of one operon.
\end{abstract}

\section{INTRODUCTION}

The membrane-bound Bacillus subtilis succinate dehydrogenase complex [EC 1.3.99.1, succinate : (acceptor) oxidoreductase] contains equimolar amounts of three subunits: a $M_{\mathrm{r}} 65000$ flavoprotein (Fp), a $M_{\mathrm{r}} 28000$ iron protein (Ip) and cytochrome $b_{558}$ (Hederstedt et al., 1979). We have isolated and characterized about $30 \mathrm{~B}$. subtilis succinate dehydrogenase-negative mutants. All these mutants contain at least one of the subunits of the succinate dehydrogenase (SDH) complex, and the respective mutations all map in the $s d h$ region (formerly called cit $F$ ) (Hederstedt et al., 1982). Mapping data from transformation crosses with SDH-negative mutants together with the phenotypes of the mutants, as well as results from reconstitution of active SDH by protoplast fusion of SDH-negative mutants, suggest that the $s d h$ region contains the structural genes for the subunits of the SDH complex in the order $s d h A$ (cytochrome $b_{558}$ )$s d h B(\mathrm{Fp})-s d h C(\mathrm{Ip})-i l v C 1$-leu-2 (Ohné et al., 1973; Hederstedt \& Rutberg, 1981; Hederstedt et $a l ., 1982)$. In the present paper we describe a pleiotropic SDH-negative mutant of $B$. subtilis which lacks all subunits of the SDH complex. The properties of this mutant suggest that the structural genes for cytochrome $b_{558}, \mathrm{Fp}$, and Ip constitute an $s d h$ operon.

\section{METHODS}

Bacteria. The Bacillus subtilis strains used are listed in Table 1. Mutation sdh-115 was isolated from B. subtilis 168 spores mutagenized with ethyl methanesulphonate as described by Ito \& Spizizen (1971). Strain KA95115 was constructed by transforming KA20 with $s d h-115$ DNA with primary selection for leucine prototrophy. Strain KA 120 was constructed as follows. About $10^{8}$ B. subtilis 168 were plated on minimal medium containing $100 \mu \mathrm{g}$ $S$-(2-aminoethyl)cysteine (Aec) $\mathrm{ml}^{-1}$. Ten independent Aec-resistant mutants were isolated. DNA was extracted from these mutants and used to transform BR95 to isoleucine-valine prototrophy at limiting DNA concentration. About 200 transformants from each cross were tested for Aec resistance. In one cross about $30 \%$ of the transformants were Aec-resistant, whereas no resistant transformants were found in the other nine crosses. The aec mutation linked to ile Cl was assumed to be located in the aecA locus (Mattioli et al., 1979) and was designated aecA5. One Aec-resistant isoleucine-valine prototroph from the above cross was kept and designated KA120.

Media. The bacteria were kept on Tryptic Blood Agar Base plates (Difco). The SDH phenotype was checked on Purification agar (Carls \& Hanson, 1971) which differentiates between acid-excreting (e.g. SDH mutants) and non-excreting (wild-type) strains of $\boldsymbol{B}$. subtilis. Spizizen's minimal medium was used (Spizizen, 1958). Required

Abbreviations: Aec, $S$-(2-aminoethyl)cysteine; SDH, succinate dehydrogenase; Fp, flavoprotein; Ip, iron protein. 
Table 1. Bacteria

\begin{tabular}{|c|c|c|}
\hline Strain & Genotype & Source or reference \\
\hline 168 & $\operatorname{trp} C 2$ & J. A. Hoch \\
\hline BR95 & $\operatorname{trpC2}$ ilvCl pheAl & J. Spizizen \\
\hline BR102 & $\operatorname{trp} C 2$ his $B$ & J. Spizizen \\
\hline KA20 & $\operatorname{trpC2}$ leu-2 ilvCl & This laboratory \\
\hline KAl11 & ilv $C 1$ phe $A 1$ met $B 5$ & This laboratory \\
\hline $\mathrm{KA} 120$ & trpC2 phe Al aec $A 5$ & This laboratory \\
\hline KA98011 & $\operatorname{sdhB11} \operatorname{trp} C 2$ & Ohné et al. (1973) \\
\hline KA98012 & $s d h A 12 \operatorname{trp} C 2$ & Ohné et al. (1973) \\
\hline KA98069 & $\operatorname{sdhB69} \operatorname{trpC2}$ & Ohné et al. (1973) \\
\hline KA95069 & $\operatorname{sdhB69}$ trpC2 ilvCl & Hederstedt et al. (1982) \\
\hline KA98078 & $\operatorname{sdhA} 78 \operatorname{trp} C 2$ & Ohné et al. (1973) \\
\hline KA95078 & sdhA78 trpC2 ilv Cl & Hederstedt et al. (1982) \\
\hline KA93078 & sdhA78 aec A5 & This work \\
\hline KA98083 & $s d h C 83 \operatorname{trp} C 2$ & Ohné et al. (1973) \\
\hline KA97083 & $s d h C 83$ trpC 2 leu-2 & Ohné et al. (1973) \\
\hline KA95083 & sdhC83 trpC2 ilvCl & Hederstedt et al. (1982) \\
\hline KA98115 & $s d h-115 \operatorname{trpC2}$ & This work \\
\hline KA95115 & $s d h-115$ trpC2 ilv Cl & This work \\
\hline CU1886 & $\arg A 2$ phe $A 2$ attSP $\beta$ cit $F:: \operatorname{SP} \beta C 2$ & Mackey \& Zahler (1982) \\
\hline CU2058 & (metB5) dal-1(SP $\beta C 2)(\mathrm{SP} \beta C 2$ int 5 dsup3-1) & Lipsky et al. (1981) \\
\hline CU2059 & (met B5) dal-1(SP $\beta C 2)(\mathrm{SP} \beta C 2$ int 5 dsup44-1) & Lipsky et al. (1981) \\
\hline
\end{tabular}

amino acids were added at $20 \mathrm{mg} \mathrm{l}^{-1}$. SDH-positive revertants of KA95115 were isolated from cultures grown with shaking at $37^{\circ} \mathrm{C}$ in $\mathrm{CY}$ medium (minimal medium with the following supplements per litre: $5 \mathrm{~g}$ casein hydrolysate, $2.5 \mathrm{~g}$ yeast extract, and $20 \mathrm{mg}$ of any amino acid required). CYG is $\mathrm{CY}$ medium with $5 \mathrm{~g}$ glucose added per litre.

Transformation. Extraction of DNA, determination of DNA concentration, and two- and three-factor transformation crosses were made as described by Ohné et al. (1973). Competent cells were prepared as described by Arwert \& Venema (1973). Ilv $^{+}$transformants were selected on minimal plates without isoleucine-valine and with glucose $\left(5 \mathrm{~g} \mathrm{t}^{-1}\right)$ as carbon and energy source. Aec-resistant transformants were selected on minimal medium containing glucose, required amino acids and $100 \mu \mathrm{g} \mathrm{Aec} \mathrm{ml}^{-1}$. Selection for $\mathrm{Sdh}^{+}$transformants in the cross

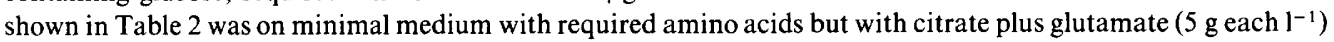
as carbon and energy source instead of glucose. All SDH mutants of $B$. subtilis fail to grow on citrate plus glutamate probably partly due to an inability to synthesize aspartate.

Other methods. The following methods have recently been described in detail. Preparation and characterization of anti-SDH antisera and quantitation of SDH protein by rocket immunoelectrophoresis (Holmgren et al., 1979; Hederstedt \& Rutberg, 1980; Owen, 1981), reconstitution of active SDH by protoplast fusion of SDH-negative mutants (Hederstedt et al., 1982), spectroscopic determination of cytochrome $b_{558}$ (Hederstedt, 1980). SDH enzyme activity was measured by a modification (Hederstedt et al., 1979) of the method of Ells (1959). Protein was determined by the Lowry method with bovine serum albumin as standard.

\section{RESULTS AND DISCUSSION \\ Phenotype of KA95115}

Strain KA95115 which carries the mutation $s d h-115$ lacks in vitro SDH enzyme activity, excretes acid and cannot use glutamate plus citrate as carbon and energy source.

Three methods were used to detect the individual subunits of the membrane-bound SDH complex: spectroscopy (cytochrome $b_{558}$ ), subunit specific antibody (against Fp and Ip), and reconstitution of SDH by protoplast fusion of pairs of SDH-negative mutants (Hederstedt, 1980; Hederstedt \& Rutberg, 1980; Hederstedt et al., 1982). In KA95115 we could not detect any cytochrome $b_{558}$ chromophore. The strain does not contain any Fp or Ip subunits, or fragments thereof, that could be recognized by our subunit-specific antibodies. Active SDH was reconstituted when protoplasts from strains carrying either mutations $s d h A 12$ (cytochrome $b_{558}$ defective), $s d h B 11$ (Fp defective), or $s d h C 83$ (Ip defective) were fused with one another (Hederstedt et al., 1982). No reconstitution of SDH was obtained when KA95115 was fused with 


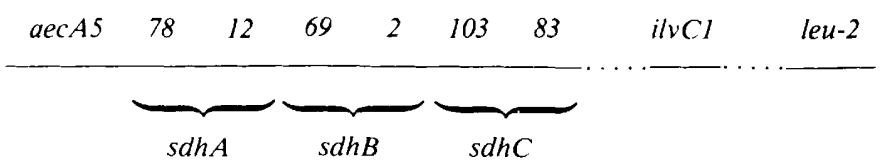

Fig. 1. Map of the sdh region in Bacillus subtilis.

Table 2. Mapping of sdh-115 with three-factor transformation crosses

At least 208 transformants were picked and tested for the non-selected marker.

\begin{tabular}{|c|c|c|c|c|c|}
\hline \multicolumn{2}{|c|}{ Genotype } & \multirow{2}{*}{$\begin{array}{c}\text { Selected } \\
\text { phenotype }\end{array}$} & \multirow{2}{*}{$\begin{array}{l}\text { Recombinant } \\
\text { class }\end{array}$} & \multirow[b]{2}{*}{$\%$} & \multirow[b]{2}{*}{ Order implied } \\
\hline Donor & Recipient & & & & \\
\hline$s d h-115$ & sdhC83 ilvCl & $\mathrm{Ilv}^{+}$ & $\mathrm{Sdh}^{+} \mathrm{Ilv}^{+}$ & $9 \cdot 4$ & sdhC83 ill Cl \\
\hline$s d h C 83$ & sdh-115 ilvCI & $\mathrm{Ilv}^{+}$ & $\mathrm{Sdh}^{+} \mathrm{Ilv}^{+}$ & $2 \cdot 0$ & \\
\hline$s d h-115$ & sdhB69 ilvCl & $\mathrm{Ilv}^{+}$ & $\mathrm{Sdh}^{+} \mathrm{Ilv}^{+}$ & $6 \cdot 3$ & $s d h-115$ \\
\hline$s d h B 69$ & sdh-115 ilvCl & $\mathrm{Ilv}^{+}$ & $\mathrm{Sdh}^{+} \mathrm{Ilv}^{+}$ & $2 \cdot 7$ & \\
\hline$s d h-115$ & sdhA78 ilvCl & $\mathrm{Ilv}^{+}$ & $\mathrm{Sdh}^{+} \mathrm{Ilv}^{+}$ & $2 \cdot 9$ & $s d h-115$ \\
\hline sdhA78 & sdh-115 ilv C1 & $\mathrm{Ilv}^{+}$ & $\mathrm{Sdh}^{+} \mathrm{Ilv}^{+}$ & 0.7 & \\
\hline aecA5 sdhA78* & $s d h-115$ & $\mathrm{Sdh}^{+}$ & $\mathrm{Aec}^{\mathrm{R}} \mathrm{Sdh}^{+}$ & 91 & $s d h-115$ \\
\hline & & & $\mathrm{Aec}^{\mathrm{S}} \mathrm{Sdh}^{+}$ & 9 & \\
\hline & & $\operatorname{Aec}^{R}$ & $\mathrm{Aec}^{\mathrm{R}} \mathrm{Sdh}^{+}$ & 53 & \\
\hline & & & $\mathrm{Aec}^{\mathrm{R}} \mathrm{Sdh}^{-}$ & 47 & \\
\hline
\end{tabular}

* This donor strain was isolated from the crosses shown in Table 3.

any of these strains. From these negative results we conclude that KA95115 does not contain any of the subunits of the SDH complex.

\section{Mapping of sdh-115 by transformation}

A number of $B$. subtilis $s d h$ mutations have been mapped by three-factor transformation crosses with primary selection for the linked markers ilvCl or leu-2 (Ohné et al., 1973; Hederstedt et al., 1982). An abbreviated map of the $s d h$ region is shown in Fig. 1. In three-factor transformation crosses with primary selection for isoleucine-valine prototrophy $s d h-115$ mapped outside $s d h A 78$ at one extreme of the $s d h$ region (Table 2).

The aec $A$ gene determines resistance to the lysine analogue Aec. Three-factor transformation crosses have established the order aecA-ilvC-leu-8 (Mattioli et al., 1979) and aec $A$ has been placed between $s d h(c i t F)$ and $i l v C$ in the map of Henner \& Hoch (1980). We have re-examined the position of aecA in three-factor transformation crosses with ilvC and $s d h A 78$. The results of these crosses clearly give the order aecA5 - sdhA78 - ilvCl (Table 3) with about $70 \%$ co-transformation of aecA5 and $s d h A 78$.

To confirm the position of $s d h-115$, aecA5 was used as an outside marker. In a two-factor cross with aecA5 donor DNA and KA95115 as recipient, all Aec-resistant transformants tested (64/64) were SDH-positive. KA95115 was next transformed with aecA5 sdhA78 donor DNA. SDH-positive or Aec-resistant transformants were selected and the distribution of the unselected marker was determined. The results of these crosses are compatible with the order aecA5-sdh-115 - sdhA78 (Table 2). For reasons not at present understood, we cannot transform a strain carrying $s d h A 78$ with aec $A 5 s d h-115$ donor DNA.

\section{Mutation sdh-115 is not suppressed by suppressors sup-3 or sup-44}

The pleiotropic nature of KA95115 may be due to a polar effect. Although the mechanism of extra-genic suppression is not well known in B. subtilis (Smith, 1982), we considered it of interest to determine if $s d h-115$ was suppressed by either of the suppressors sup-3 or sup-44. Mutation $s d h-115$ was introduced into strain KA111 which carries the suppressor-sensitive mutation metB5. The bacteria were infected with high frequency transducing SP $\beta$ sup-3 or sup-44 lysates 
Table 3. Mapping of aecA5 with three-factor transformation crosses

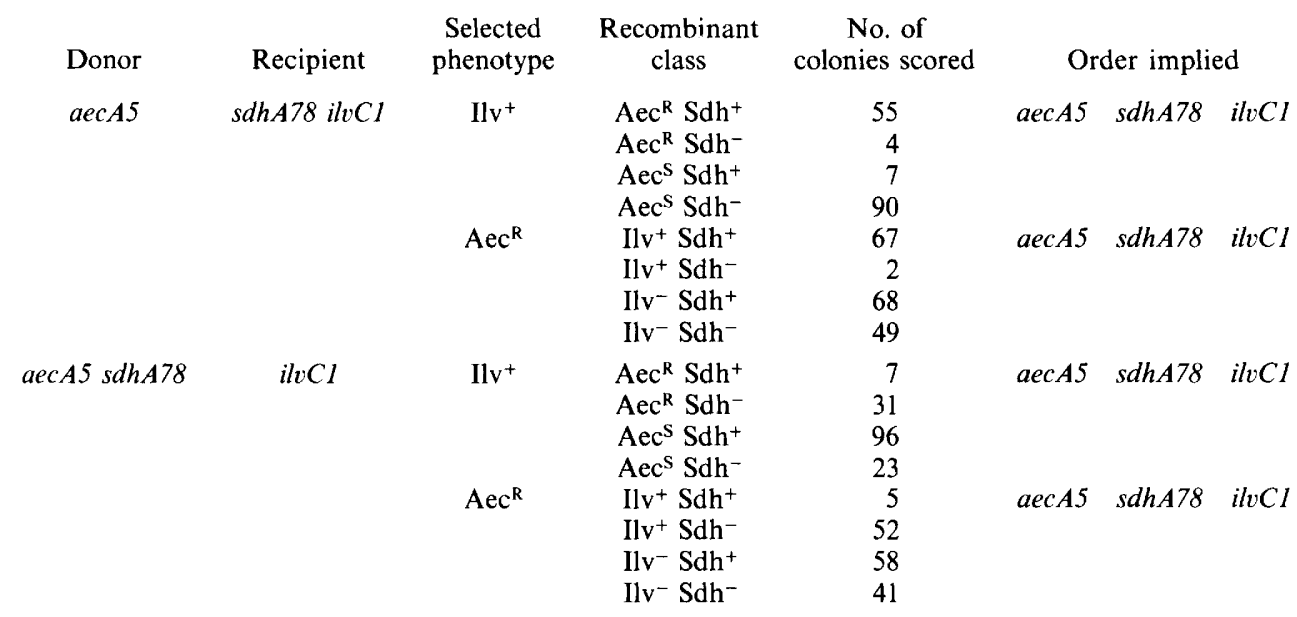

and methionine prototrophs were selected (Lipsky et al., 1981). Five prototrophs were purified and the presence of the suppressor gene was verified by cross-streaking against phage SPO2 carrying the suppressor-sensitive mutation susL244 (Yasunaka et al., 1970). However, the suppressor-carrying strains were still SDH-negative.

\section{Reversion of sdh-115}

When KA95115 is grown in CY medium more rapidly growing wild-type revertants accumulate. Five independent revertants of KA95115 were isolated by plating KA95115 grown in CY medium on Purification agar. The amount of SDH enzyme activity in these revertants and in wild-type bacteria (strain BR 102) grown in CY and CYG medium was measured. In all cases enzyme activity was proportional to the amount of enzyme protein measured by rocket immunoelectrophoresis of Triton X-100 solubilized SDH using anti-Fp antibody (Rutberg et al., 1978; Hederstedt et al., 1979; Owen, 1981). All revertants were sensitive to glucose repression of SDH although to various degrees.

\section{Control of $S D H$}

Synthesis of the three subunits of the SDH complex in $B$. subtilis must be carefully controlled and coordinated. Equimolar amounts of $\mathrm{Fp}$, Ip, and cytochrome $b_{558}$ are found in the complex and no, or very few, free subunits are present in wild-type cells (Hederstedt \& Rutberg, 1980). SDH activity is repressed by glucose in B. subtilis (Hanson \& Cox, 1967; Ohné, 1975) as it is in Escherichia coli (Ruiz-Herrera \& Garcia, 1972; Takahashi, 1975). In B. subtilis, SDH enzyme activity and amount of enzyme protein show very good correlation. Furthermore, the synthesis of inactive subunits in SDH-negative B. subtilis mutants was repressed by glucose which shows that glucose affects the synthesis of enzyme protein (unpublished results). The extent of glucose repression can vary considerably for different genes: in $B$. subtilis grown in the presence of glycerol and glucose, glycerolphosphate dehydrogenase was repressed about 30-fold compared to its level in bacteria grown with only glycerol, whereas glycerol kinase was only repressed fivefold (Lindgren \& Rutberg, 1974). The respective genes are closely linked, but they are probably in separate operons (Lindgren \& Rutberg, 1976). Glucose represses all three subunits of the $B$. subtilis SDH complex equally. This would seem most easily accomplished if the respective genes were part of a single operon.

KA95115 lacks all subunits of the SDH complex. Mutation sdh-115 maps outside all previously mapped mutations in $s d h A$ the proposed structural gene for cytochrome $b_{558}$. There are two simple explanations for the pleiotropic effect of $s d h-115$. (i) It is a strong polar mutation in the $s d h A$ gene or (ii) it is a mutation in a $s d h$ promotor region. Although our present data do 
not permit us to distinguish between these alternatives, they both require that $s d h A, s d h B$ and $s d h C$ form one operon which is transcribed in that order.

Mackey \& Zahler (1982) have isolated an SDH-negative mutant of $B$. subtilis which has phage SP $\beta$ inserted into the $s d h$ region. This mutant also lacks all subunits of the SDH complex (unpublished results). Although the exact point of insertion of the phage is not known this result supports the idea of an $s d h$ operon.

Organization into operons of the genes coding for membrane-bound protein-complexes has been demonstrated for the Escherichia coli $\mathrm{H}^{+}$-ATPase (unc) (Downie et al., 1979; Gunsalus et al., 1982) and the high affinity $\mathrm{K}^{+}$transport system (Rhoads et al., 1978; Wieczorek \& Altendorf, 1979). It may be worth noting that in both the proposed B. subtilis sdh operon and in the $E$. coli unc operon, the genes coding for the most hydrophobic subunits seem to be transcribed and translated first. This may be of importance, as recently suggested by Walker $e t$ al. (1982), for assembly of the complexes in the respective membranes.

This work was supported by grants from the Swedish Medical Research Council and from Karolinska institutets forskningsfonder. Skillful technical assistance was provided by Sven-Åke Franzén and Kerstin Andreasson. We are grateful to Dr S. A. Zahler for sending us the B. subtilis strain CU1886 which carries SP $\beta$ inserted in the $s d h$ region.

\section{REFERENCES}

ARWert, F. \& VenEma, G. (1973). Transformation in Bacillus subtilis. Fate of newly introduced transforming DNA. Molecular and General Genetics 123, 185198.

Carls, R. A. \& Hanson, R. S. (1971). Isolation and characterization of tricarboxylic acid cycle mutants of Bacillus subtilis. Journal of Bacteriology 106, 848855.

Downie, J. A., Gibson, F. \& Cox, G. B. (1979). Membrane adenosine triphosphatases of prokaryotic cells. Annual Review of Biochemistry 48, 103-131.

ElLS, H. A. (1959). A colorimetric method for the assay of soluble succinic dehydrogenase and pyridinenucleotide-linked dehydrogenases. Archives of Biochemistry and Biophysics 85, 561-562.

Gunsalus, R. P., Brusilow, W. S. A. \& Simoni, R. D. (1982). Gene order and gene-polypeptide relationships of the proton-translocating ATPase operon (unc) of Escherichia coli. Proceedings of the National Academy of Sciences of the United States of America 79, 320-324.

HaNSON, R. S. \& Cox, D. P. (1967). Effect of different nutritional conditions on the synthesis of tricarboxylic acid cycle enzymes. Journal of Bacteriology 93, $1777-1787$.

HederstedT, L. (1980). Cytochrome $b$ reducible by succinate in an isolated succinate dehydrogenase cytochrome $b$ complex from Bacillus subtilis membranes. Journal of Bacteriology 144, 933-940.

Hederstedt, L. \& Rutberg, L. (1980). Biosynthesis and membrane binding of succinate dehydrogenase in Bacillus subtilis. Journal of Bacteriology 144, 941951.

Hederstedt, L. \& Rutberg, L. (1981). Succinate dehydrogenase - a comparative review. Microbiological Reviews 45, 542-555.

Hederstedt, L., Holmgren, E. \& Rutberg, L. (1979). Characterization of a succinate dehydrogenase complex solubilized from the cytoplasmic membrane of Bacillus subtilis with the nonionic detergent Triton X-100. Journal of Bacteriology 138, 370-376.
Hederstedt, L., Magnusson, K. \& Rutberg, L. (1982). Reconstitution of succinate dehydrogenase in Bacillus subtilis by protoplast fusion. Journal of Bacteriology 152, 157-165.

Henner, D. J. \& Hoch, J. A. (1980). The Bacillus subtilis chromosome. Microbiological Reviews 44, 5782.

Holmgren, E., Hederstedt, L. \& Rutberg, L. (1979). Role of heme in synthesis and membrane binding of succinic dehydrogenase in Bacillus subtilis. Journal of Bacteriology 138, 377-382.

Ito, J. \& SpIzizen, J. (1971). Increased rate of asporogenous mutations following treatment of Bacillus subtilis spores with ethyl methanesulfonate. Mutation Research 13, 93-96.

LINDGREN, V. \& RUTBERG, L. (1974). Glycerol metabolism in Bacillus subtilis: gene-enzyme relationships. Journal of Bacteriology 119, 431-442.

LINDGREN, V. \& RUTBERG, L. (1976). Genetic control of the glp system in Bacillus subtilis. Journal of Bacteriology 127, 1047-1057.

LiPSKy, R. H., Rosenthal, R. \& ZAHLER, S. A. (1981). Defective specialized SP $\beta$ transducing bacteriophages of Bacillus subtilis that carry the sup-3 or sup44 gene. Journal of Bacteriology 148, 1012-1015.

MACKEY, C. J. \& ZAHLER, S. A. (1982). Insertion of bacteriophage $\operatorname{SP} \beta$ into the cit $F$ gene of Bacillus subtilis and specialized transduction of the ilv $B C$-leu genes. Journal of Bacteriology 151, 1222-1229.

Mattioli, R., Bazzicalupo, M., Federici, G., GalLORI, E. \& Polsinelli, M. (1979). Characterization of mutants of Bacillus subtilis resistant to $S$-(2aminoethyl)cysteine. Journal of General Microbiology 114, 223-225.

OHNÉ, M. (1975). Regulation of the dicarboxylic acid part of the citric acid cycle in Bacillus subtilis. Journal of Bacteriology 122, 224-234.

OHNÉ, M., RutberG, B. \& Hoch, J. A. (1973). Genetic and biochemical characterization of mutants of Bacillus subtilis defective in succinate dehydrogenase. Journal of Bacteriology 115, 738-745. 
OWEN, P. (1981). Immunology of the bacterial membrane. In Organization of Prokaryotic Cell Membranes, vol. 1, pp. 73-164. Edited by B. K. Ghosh. Boca Raton, Florida: CRC Press.

Rhoads, D. B., Laimins, L. \& Epstein, W. (1978). Functional organization of the $k d p$ genes of Escherichia coli K-12. Journal of Bacteriology 135, 445-452.

Ruiz-Herrera, J. \& Garcia, L. G. (1972). Regulation of succinate dehydrogenase in Escherichia coli. Journal of General Microbiology 72, 29-35.

Rutberg, B., Hederstedt, L., Holmgren, E. \& RutBerg, L. (1978). Characterization of succinic dehydrogenase mutants of Bacillus subtilis by crossed immunoelectrophoresis. Journal of Bacteriology 136, 304-311.

Sмітн, I. (1982). The translational apparatus of Bacillus subtilis. In The Molecular Biology of the Bacilli, vol. 1, pp. 111-145. Edited by D. A. Dubnau. New York: Academic Press.

SPIZIZEN, J. (1958). Transformation of biochemically deficient strains of Bacillus subtilis by deoxyribo- nucleate. Proceedings of the National Academy of Sciences of the United States of America 44, 10721078.

TAKAHASHI, Y. (1975). Effect of glucose and cyclic adenosine $3^{\prime}, 5^{\prime}$-monophosphate on the synthesis of succinate dehydrogenase and isocitrate lyase in Escherichia coli. Journal of Biochemistry 78, 10971100.

Walker, J. E., Saraste, M. \& Gay, N. J. (1982). E. coli $\mathrm{F}_{1}$-ATPase interacts with a membrane protein component of a proton channel. Nature, London $\mathbf{2 9 8}$, $867-869$.

Wieczorek, L. \& Altendorf, K. (1979). Potassium transport in Escherichia coli. Evidence for a $\mathrm{K}^{+}$transport adenosine-5'-triphosphatase. FEBS Letters 98, 233-236.

Yasunaka, K., Tsukamoto, H., Okubo, S. \& HoriuCHI, T. (1970). Isolation and properties of suppressor-sensitive mutants of Bacillus subtilis bacteriophage SPO2. Journal of Virology 5, 819-821. 